twice, relaxed. Urine: specific gravity 1018, acid, no albumen. Physical signs in the chest improving.

29 th. - Temperature $97 \cdot 7^{\circ}$; pulse 100 ; respiration 24 . Cough less troublesome; heart-sounds better, the first sound being much louder than the second. Brandy to be reduced to three ounces daily.

30 th. - Temperature $964^{\circ}$; pulse 88 ; respiration 20. Sleeping; occasionally grinds his teeth. Has asked for solid food. Bowels not open.

Oct. 1st. - Temperature $96.8^{\circ}$; pulse 96 ; respiration 16 . Looks better; cough less troublesome; heart-sounds clearer.

2nd. - Temperature $964^{\circ}$; pulse 96 ; respiration 20 . General condition much improved. Speaks rationally. Tongue steady, but still dry. Asks for solid food. Bowels open once; less relaxed.

4th. - Temperature $96.8^{\circ}$; pulse 84 , small and feeble; respiration 24. Slept well. Bowels open.

5th.-Iast evening he became delirious, frequently trying to get out of bed. Was given brandy and nourishment; then he became quiet, and slept well. Temperature $97 \cdot 1^{\circ}$; pulse 84 , very weak, rather small; respiration 18 . No return of the delirium. Ordered brandy to be increased to six ounces daily, and custard pudding instead of two eggs.

8th.-Temperature $98.2^{\circ}$; pulse 108 , soft and small; respiration 24. Tongue becoming moist; sleeps on his side; dejections semi-solid.

10th.-Ordered fish.

11th.-Ordered eight ounces of wine instead of the brandy.

12th.-Temperature $97^{\circ}$; pulse 78 ; respiration 20 . Progressing well. Pupils small; cardiac sound is a little prolonged at the apex.

14th.-Temperature $96.8^{\circ}$; pulse 90 , small, and weak; respiration 20. Talks and mutters a little during sleep. Ordered a chop instead of fish ; one grain of quinine thrice a day instead of the draught ordered Sept. 21 st.

19th.-Temperature $97 \cdot 2^{\circ}$; pulse 96. Progresses well Pupils large; heart-sounds clear, but weak. Bowels open last on the 16th. Was up yesterday for the first time. From this date convalescence rapidly progressed.

Nov. 3rd.-Still rather weak and thin. Heart-sounds quite normal. Sent to a convalescent home.

\section{STATION HOSPITAL, COLCHESTER.}

POPLITEAL ANEURTSM; INSTRUMENTAL AND MANUAL COMPRESSION ; CURE.

(Under the care of Surgeon Vivias Wearne.)

GUNNER H. G-, aged forty-eight years, an artilleryman, was admitted by Surgeon-Major Mitchell, on the 4th December, 1876. $\mathrm{He}$ stated that two months ago, after gun-drill, he experienced pain in the calf of the right leg. Gun-drill was an unusual exertion for him, as he worked in the tailor's shop. During the six weeks following the gundrill he suffered at intervals from pain in the calf of the right leg. A fortnight ago he noticed pulsation in the right ham; from then the pain had been continuous in the ham and leg; he could not walk without pain, as the right leg was very stiff.

On admission the man presented an intemperate and prematurely aged appearance. There was an aneurism about the size of a billiard-ball in the right popliteal space; it was situated on the lower part of the course of the vessel, and pulsated strongly; the sac was thin, and the contents fluid. He was of an irritable, nervous disposition. Heart's action weak ; circulation feeble. He was subject to cold extremities. Urine, sp. gr. 1030, alkaline, loaded with phosphates, the result of a chronic stricture. He has recently been in hospital for delirium tremens, and also for stricture of urethra.

Taking into consideration the debilitated condition of this man's healtb, and the weak state of his circulatory system, it was deemed advisable in treating the aneurism to employ compression, the process to extend for a period of many days. Treatment was commenced on the 9th of December. A tourniquet was applied to the femoral artery in Scarpa's triangle, so as to diminish the circulation through the aneurism very perceptibly. Compression was continued for fourteen hours, and omitted at nighttime.

The pad of the tourniquet irritated the skin, and on the 10th nine pounds of shot in a conical case was applied to the artery at the brim of the pelvis, by which means the pulsation in the aneurism was well controlled. Compression kept up fourteen hours.

Next day he complained of pain around the knee and extending down the leg.

From the 9 th compression was employed fourteen hours daily, chiefly by the shot-bag, which he bore well. On the 17 th the aneurism felt more solid.

On the $20 \mathrm{th}$, in addition to the compression exercised by the shot-bag, manual pressure for three hours was begun, when the circulation through the sac was arrested.

On the 21st manual compression for four hours, and the shot-bag applied for ten bours more.

The same treatment on the 22nd. Cramps and pains in the leg became very severe, and were not relieved by full doses of chloral. When manual compression was omitted there was lessened pulsation in the aneurism, but the foot was cold and the pains very severe. The foot was wrapped in cotton-wool and flannel bandages.

On the 23rd be looked haggard and worn; his health had suffered much in the last week, his nights were sleepless, and he was irritable and could not endure pain. It was resolved to discontinue manual compression until his condition was stronger. The shot-bag and tourniquet were applied fourteen hours daily.

For fourteen hours daily since the $23 \mathrm{rd}$ the circulation through the aneurism was lessened. The result of the treatment was that on Jan. 3rd the aneurism felt more solid and the pulsation had diminished. The man's general health had improved. At 2 P M. (Jan. 3rd), manual pressure was begun by relays of orderlies, and the circulation through the aneurism arrested. At 6 P M. slight pulsation only was felt. At 9 P.M. pulsation ceased in the aneurism, the temperature of the limb fell slightly, and the leg became swollen. The orderlies were dismissed, but the patient remained awake all night and applied pressure to the shot-bag.

No pulsation was perceptible in the sac next day. Tourniquet applied during the day.

On the 6 th the aneurism was smaller, and felt solid. The swelling of the leg was gradually decreasing; a small artery beat perceptibly over the head of the fibula; collateral circulation established; shot-bag applied during the day.

On the 12 th there was no return of pulsation. Compression was omitted on the $17 \mathrm{th}$, when the man was convalescent. He was up and dressed on the 20 th and walking about the ward.

Remarks.-Considering the broken-down state of health and diseased condition of the circulatory system, produced by alcholism, in this patient, it is very doubtful whether the rapid method of curing the aneurism could have succeeded. Until the collateral circulation was established by gradual compression continued for some time, it was not thought advisable to arrest the circulation through the aneurism too suddenly.

\section{HOSPITAL FOR WOMEN AND CHILDREN, CORK.}

CYST CONNECTED WITH THE THYROID BODY PRODUCING SUFFOCATIVE SYMPTOMS; ENUCLEATION ; RECOVERY.

(Under the care of Dr. H. Macnadghton Jones.)

M. D-, aged forty, had been in another institution, and was discharged without material relief. She was sent to this hospital in July, 1876. She then suffered from difficulty of breathing, and complained of distress occasioned by the pressure of the tumour on the trachea. The tumour was about the size of a hen's egg. Finding the cyst movable Dr. Jones determined to enucleate it. This he did on the 19th of July, assisted by his colleagues, Drs. Cummins and Curtis. The eyst was pushed well up from the episternal depression into the neck, and a preliminary incision, about three inches long, was made a little to the left of the mesial line. Dr. Cummins retained the cyst in this position with a fine tenaculum during the operation. No anæsthetic was given. With a narrow scalpel and a fine blunt-pointed 
tenotome the cyst was cautiously exposed, and pushed forward into the wound. The dissection was continued with the narrow knife and the handle of the tenotome, each bloodvessel being ligatured as it came into view, and a few small ones were twisted. When all the vessels were tied, the cyst was finally enucleated, and when the bleeding was complettly stopped, the wound was brought together with some wire sutures, and dressed with salicylic dressings, which were continued until the wound healed. The patient was dismissed on August 14th.

\section{EXCISION OF NECK OF FEMUR.}

There is at present in the bospital a case of excision of the neck of the femur in a child for old-standing necrosis associated with abscess over the trochanter, which had been repeatedly aspirated. The child is up to the present doing well. The operation was done according to Lister's antiseptic method.

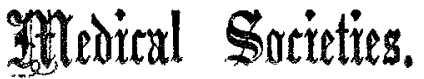

\section{ROYAL MEDICAL AND CHIRURGICAL SOCIETY.}

The ordinary meeting of this Society was held on the 13th inst., Dr. Charles West, President, in the chair. An ela. borate paper by Dr. Gowers and Mr. Sankey was read, dealing with the pathological anatomy of "Canine Chorea;" the paper was illustrated by a series of microscopical preparations. A brief note by Mr. Wilkes, of Salisbury, on an unsual case of stone in the bladder, and a paper by Mr. Barwell upon congenital dislocations of the knee, were also read.

Dr. WEST, on taking the chair as President for the first time, acknowledged with hearty thanks his sense of the honour done him by the Society. To be chosen President of that Society was, be considered, the highest bonour to which any member of the profession could aspire. Although he felt some misgivings in having to follow so closely upon his eminent predecessor, he would have the advantage of the Society's seventy years of tradition to guide him in maintaining its honour and dignity.

A paper was read on "The Pathological Anatomy of Canine Chorea," by Dr. W. R. Gowers and Mr. H. R. O. Sankey. The paper contains an account of the changes found in the nerve-centres in two cases of the disease of the dog which has been termed chorea, although it bears but little resemblance to the chorea of man. It consists of quick muscular contractions, separated by an interval, and without incoordination, or fidgety movement. In the two cases the move ments were similar. In one they were confined to one foreleg, and the changes found in the nerve-centres were slight, the medulla oblongata presenting nothing abnormal. In the spinal cord the large nerve-cells of the cervical region were very granular and appeared swollen, the body of the cell being in some instances apparently distended with granules so that it bad an almost globular form. This change was more marked on the right side than on the left. In the upper part of the cervical region there was a slight increase in the minute nuclei of the anterior column on the right side. In the upper lumbar region the nerve-cells of the right posterior vesicular column were much more granular than those of the left. In the other case, a young retriever, the twitchings were general and had commenced (in one foreleg) after distemper, two months before death. They were more marked when the animal was at rest, and were accompanied with considerable weakness; in the limbs, especially the bind limbs, sensation was considerably diminished, the posterior balf of the trunk and hind limb being quite insensitive. The muscles of the neck and those of the larynx, tongue, and jaw were involved in the twitching. After death the heart, the muscles, and the cerebral hemispheres with the central ganglia were healtby. Microscopic examination showed extensive disease in the spinal cord, medulla oblongata, and cerebellum. The most conspicuous change was an infiltration of small round lymphoid cells, precisely resembling white blood-corpuscles. Areas so infiltra ed were found abundantly in both white and gres substance in all parts of the cord, the distribution varying much : in some parts in the lateral, in others in the anterior: in others in the posterior columns. In places the anterior, in others the posterior grey cornua were infiltrated. In some places the nerve-tissue appeared disintegrated and destroyed, but there the infiltration was slighter; it was in the form of ramifying tracts, always corresponding to the course of vessels. From this the authors are inclined to regard it as a leucocytal infiltration. The nerve-cells in many parts ap. peared healthy, but in others were very granular, and in some parts were surrounded by the lymphoid cells. Some nerve-cells had a granular centre and an ill-defined boun. dary. The protoplasm of many was encroached on by vacuoles, partly outside the cells. These had in places almost destroyed the cells. They appeared formed during the process of hardening, but the authors suggest that they are of patholngical siguificance, since they were absent in another cord similarly prepared. In the medulla oblongata the changes were similar but slighter, and confined to scattered areas of cellular infiltration. A similar infiltration existed extensively in the medulla of the cerebellum, and was in some places very dense. The cortex of the cerebellum, however, was healthy. In each $d n g$ the effect of section of the cord was observed. In the sligbter case Dr. Hugh. lings Jacksnn had noted that the movements contirued for a few moments after pithing. In the other, in which the changes in the cord were extensive, artificial respiration was kept up after division of the cord, and no movements occurred in the parts below the section, although they con. tinued in the muscles of the head and jaw. In other recorded cases, however, similar movements have been ob. served to persist after the section of the cord. It is remarkakle, therefore, that in this case, in which the cord was so diseased, the movements should have been arrested. It is possible that in some cases the movements may be encephalic (perhaps cerebellar), in others of spinal origin; but another explanation of the cessa. tion of the movements may be that the section of the cord temporarily inbibited by shock the action of the weakened nerve-cells of the cord. The cellular infiltration appears from its course to have been the result of vascular distarbance, hut whether primary or the result of functional $n$ ver-action of the nerve-elements, it is difficult to say. Its random position indicates an independent progress, and arcounts for the motor and sensory paralysis, but its limitation to the cord, medulla, and cerebellum suggests a primary dependence on functional disturbance of the nerve elements. The only morbid appearance common to the two cases was a change in the nerve-cells of the cord, and this may be regarded as the primary morbid change, the indication of their over-action, to which the vascular change and cellular infiltration are secondary in oriyiu. To decide these and other points, however, further observations are necessary.The PRESTDENT, in according to the authors a vote of thanks, said that good honest work like this was never lost, serving as materials from which hereafter some real and imprrtant conclusions may be deduced.-Dr. CADDY made scme remarks tending to show the dependence of differences in muscular power among animals upon the development of the sninal cord-Dr. JoHN HARLEY said that probably what had been found in the case of the dog would be equally anplicanle to man; and he agreed in the suggestion thrown ont by the authors of the paper, that the movements of chorea are probahly due to the intrinsic action of the nervecells, to which the vascular changes are secondary. He had himself been enabled to produce chorea artificially in the dog by the administration of the alkaloid cryptopia The movements came on about half an hour after the ab sorption of the drug, and lasted until it was eliminated. This could only be by its direct action on the nerve-cells, especially as examination of the spinal cords of animals so treated did not reveal ang evidence of intense vascular congestion or stasis.

A paper was then read on a "Case of Vesical Calculus, the nucleus of which was a piece of necrosed bone; remored by Lithotomy," by Mr. W. D. WILKES, Surgeon to the Salisbury Infirmary. The patient, M. P-, aged fifty, an agricultural labourer, a tall, thin man, was admitted in to the Salisbury Infirmary in Oct., 1876, for stone in the bladder. A small orifice to urethra and sensitive passages indicated 